\title{
AFLP fingerprinting for analysis of yeast genetic variation
}

\author{
Miguel de Barros Lopes, ${ }^{1,2,3}$ Sandra Rainieri, ${ }^{4}$ Paul A. Henschke ${ }^{1,3}$ \\ and Peter Langridge $\mathrm{e}^{2,3}$
}

Author for correspondence: Miguel de Barros Lopes. Tel: +61 88303 6643. Fax: +61 883036601 . e-mail:mlopes@waite.adelaide.edu.au

\author{
1 The Australian Wine \\ Research Institute, PO Box \\ 197, Glen Osmond, SA \\ 5064, Australia \\ 2 Department of Plant \\ Science, Waite Agricultural \\ Research Institute, The \\ University of Adelaide, SA \\ 5064, Australia \\ 3 Cooperative Research \\ Centre for Viticulture, \\ Plant Research Centre, \\ Hartley Grove, Urrbrae, SA \\ 5064, Australia \\ 4 Dipartimento di \\ Protezione e \\ Valorizzazione \\ Agroalimentare \\ (DIPROVAL), University of \\ Bologna, Villa Levi, 42100 \\ Reggio Emilia, Italy
}

\begin{abstract}
Amplified fragment length polymorphism (AFLP) was used to investigate genetic variation in commercial strains, type strains and winery isolates from a number of yeast species. AFLP was shown to be effective in discriminating closely related strains. Furthermore, sufficient similarity in the fingerprints produced by yeasts of a given species allowed classification of unknown isolates. The applicability of the method for determining genome similarities between yeasts was investigated by performing cluster analysis on the AFLP data. Results from two species, Saccharomyces cerevisiae and Dekkera bruxellensis, illustrate that AFLP is useful for the study of intraspecific genetic relatedness. The value of the technique in strain differentiation, species identification and the analysis of genetic similarity demonstrates the potential of AFLP in yeast ecology and evolutionary studies.
\end{abstract}

Keywords: AFLP, yeasts, genetic similarity

\section{INTRODUCTION}

Differences in morphological and physiological characteristics continue to be the main criteria used in yeast classification (Barnett et al., 1990). However, since many of the characters can be reversed by a mutation in a single gene, these methods, on their own, are inadequate. The use of the biological species concept, which delimits species on their ability to hybridize, is also restricted in yeast systematics. Lack of fertility does not preclude conspecificity and furthermore, hybridization studies with yeasts can be difficult and therefore not suitable for routine yeast identification (see Kurtzman \& Phaff, 1987, for review).

The limitations in using morphological and physiological methods, and the problems associated with the biological species concept in yeasts has led to the increasing use of nucleic acid methods in yeast taxonomy. Of importance has been the use of DNA reassociation studies, where genome similarities greater than $80 \%$ have been taken to indicate conspecificity

Abbreviations: AFLP, amplified fragment length polymorphism; UPGMA, unweighted pair group method with arithmetic averages.
(Price et al., 1978; Vaughan Martini \& Kurtzman, 1985). Defining the lower limit for delimiting species has been more difficult, however, as successful matings have been obtained between yeasts that show only $25 \%$ DNA similarity (Kurtzman et al., 1980). The ability of yeasts with such low levels of sequence similarity to undergo effective meiosis is not yet understood, and needs to be considered when using any DNA-based identification method. More recently, the emphasis in molecular methods has been to correlate taxonomy with phylogeny. For this purpose, sequence analysis of the rRNA genes has been widely used as their common evolutionary origin permits the comparison of both closely and distantly related species (Kurtzman, 1992).

Other molecular methods have also been used to study yeasts at both the species and subspecies level. These include chromosome karyotyping (Johnston \& Mortimer, 1986), RFLP (McArthur \& Clark-Walker, 1983; Molina et al., 1993) and PCR (de Barros Lopes et al., 1998; Ganter \& Quarles, 1997; Latouche et al., 1997; Lavallée et al., 1994). As these methods are useful for discriminating strains within a species, they are also being used in yeast ecology and epidemiology studies. In this paper, the use of amplified fragment length 
Table 1. Yeast species and strains studied

\begin{tabular}{|c|c|c|}
\hline AWRI no. & Strain details & CBS no. \\
\hline \multicolumn{3}{|c|}{ Saccharomyces cerevisiae Meyen ex E. C. Hansen } \\
\hline 1219 & Neotype strain & $1171^{\mathrm{NT}}$ \\
\hline 1350 & Laboratory yeast, FY833 MATa & \\
\hline 1351 & Laboratory yeast, FY834 MAT $\alpha$ & \\
\hline 1352 & Brewers' yeast, B431 (Brigalow Brewing Co.) & \\
\hline 1353 & Bakers' yeast, K5088 (Cerebos Ltd) & \\
\hline 939 & Sake yeast & \\
\hline 796 & Commercial wine yeast & \\
\hline 350 & Commercial wine yeast & \\
\hline 834 & Commercial wine yeast & \\
\hline 81 & Commercial wine yeast & \\
\hline 1017 & Commercial wine yeast & \\
\hline 838 & Commercial wine yeast & \\
\hline 729 & Commercial wine yeast, University of California, Davis, USA & \\
\hline 814 & $\begin{array}{l}729 \text { yeast, The Australian Wine Research Institute, South Australia, } \\
\text { Australia }\end{array}$ & \\
\hline 825 & 729 yeast, Dept of Agriculture, Western Australia, Australia & \\
\hline 835 & 729 yeast, Dept of Agriculture, Western Australia, Australia & \\
\hline 925 & 729 yeast, University of California, Davis, USA & \\
\hline 947 & $\begin{array}{l}729 \text { yeast, The Australian Wine Research Institute, South Australia, } \\
\text { Australia }\end{array}$ & \\
\hline 1116 & 729 yeast, Epernay, France & \\
\hline 1117 & 729 yeast, Epernay, France & \\
\hline 1118 & 729 yeast, Epernay, France & \\
\hline 1144 & Former type strain of Candida robusta & 1907 \\
\hline 1265 & Winery isolate, South Australia, Australia & \\
\hline 870 & Winery isolate, New South Wales, Australia & \\
\hline 871 & Winery isolate, New South Wales, Australia & \\
\hline \multicolumn{3}{|c|}{ Saccharomyces paradoxus Bachinskaya } \\
\hline 1172 & Neotype strain & $432^{\mathrm{NT}}$ \\
\hline \multicolumn{3}{|c|}{ Saccharomyces bayanus Saccardo } \\
\hline 1146 & Type strain & $380^{\mathrm{T}}$ \\
\hline 1145 & Former type strain of Saccharomyces uvarum & 395 \\
\hline 1266 & Winery isolate, South Australia, Australia & \\
\hline 948 & Winery isolate, South Australia, Australia & \\
\hline \multicolumn{3}{|c|}{ Saccharomyces pastorianus Reess ex E. C. Hansen } \\
\hline 1173 & Neotype strain & $1538^{\mathrm{NT}}$ \\
\hline \multicolumn{3}{|c|}{ Saccharomyces unisporus Jörgensen } \\
\hline 1218 & Type strain & $398^{\mathrm{T}}$ \\
\hline \multicolumn{3}{|c|}{ Saccharomyces exiguus Reess } \\
\hline 1216 & Type strain & $379^{\mathrm{T}}$ \\
\hline \multicolumn{3}{|c|}{ Saccharomyces kluyveri Phaff et al. } \\
\hline 1217 & Type strain & $3082^{\mathrm{T}}$ \\
\hline \multicolumn{3}{|c|}{ Dekkera bruxellensis van der Walt } \\
\hline 1205 & Type strain & $74^{\mathrm{T}}$ \\
\hline 1102 & Former type strain of Brettanomyces bruxellensis & 72 \\
\hline 1207 & Former type strain of Dekkera intermedia & 4914 \\
\hline 1104 & Former type strain of Brettanomyces intermedius & 73 \\
\hline 1127 & Former type strain of Brettanomyces lambicus & 75 \\
\hline 1103 & Former type strain of Brettanomyces custersii & 5512 \\
\hline 1130 & Former type strain of Brettanomyces abstinens & 6066 \\
\hline \multicolumn{3}{|c|}{ Dekkera anomala M. T. Smith et van Grinsven } \\
\hline 953 & Type strain & $8139^{\mathrm{T}}$ \\
\hline 1128 & Former type strain of Brettanomyces claussenii & 76 \\
\hline 1168 & Former type strain of Dekkera anomalus & 77 \\
\hline
\end{tabular}


Table 1 (cont.)

\begin{tabular}{|c|c|c|}
\hline AWRI no. & Strain details & CBS no. \\
\hline \multicolumn{3}{|c|}{ Brettanomyces naardenensis Kolfschoten et Yarrow } \\
\hline 951 & Type strain & $6042^{\mathrm{T}}$ \\
\hline \multicolumn{3}{|c|}{ Brettanomyces custersianus van der Walt } \\
\hline 950 & Type strain & $4805^{\mathrm{T}}$ \\
\hline \multicolumn{3}{|c|}{ Brettanomyces nana M. T. Smith et al. (Formerly Eeniella) } \\
\hline 1201 & Type strain & $1945^{\mathrm{T}}$ \\
\hline \multicolumn{3}{|c|}{ Torulaspora delbrueckii Lindner } \\
\hline 1152 & Type strain & $1146^{\mathrm{T}}$ \\
\hline 1034 & Commercial wine yeast & \\
\hline 872 & Winery isolate, New South Wales, Australia & \\
\hline \multicolumn{3}{|c|}{ Issatchenkia orientalis Kudryavtsev } \\
\hline 1220 & Type strain & $5147^{\mathrm{T}}$ \\
\hline 873 & Winery isolate, New South Wales, Australia & \\
\hline \multicolumn{3}{|c|}{ Hanseniaspora uvarum (Niehaus) Shehata et al. } \\
\hline 1158 & Type strain & $314^{\mathrm{T}}$ \\
\hline 868 & Winery isolate, New South Wales, Australia & \\
\hline 1274 & Winery isolate, South Australia, Australia & \\
\hline 1275 & Winery isolate, California, USA & \\
\hline 1276 & Winery isolate, California, USA & \\
\hline \multicolumn{3}{|c|}{ Hanseniaspora guilliermondii Pijper } \\
\hline 1200 & Type strain & $465^{\mathrm{T}}$ \\
\hline 1277 & Winery isolate, California, USA & \\
\hline \multicolumn{3}{|c|}{ Metschnikowia pulcherrima Pitt et Miller } \\
\hline 1149 & Type strain & $5833^{\mathrm{T}}$ \\
\hline 1267 & Winery isolate, South Australia, Australia & \\
\hline 1268 & Winery isolate, South Australia, Australia & \\
\hline 1269 & Winery isolate, South Australia, Australia & \\
\hline 1270 & Winery isolate, South Australia, Australia & \\
\hline \multicolumn{3}{|c|}{ Pichia fermentans Lodder } \\
\hline 1199 & Type strain & $187^{\mathrm{T}}$ \\
\hline $1271 *$ & Winery isolate, South Australia, Australia & \\
\hline \multicolumn{3}{|c|}{ Pichia membranifaciens E. C. Hansen } \\
\hline 1095 & Type strain & $107^{\mathrm{T}}$ \\
\hline $1272 *$ & Winery isolate, South Australia, Australia & \\
\hline
\end{tabular}

* Species description using standard physiological methods. Inconsistent with molecular methods.

polymorphism (AFLP) for yeast systematics is described. AFLP is a technique that is based on the selective PCR amplification of restriction fragments from a total digest of DNA (Vos et al., 1995). The main use of AFLP to date has been as molecular markers, mostly for plant breeding programmes (Thomas et al., 1995) but also for mammalian species (Otsen et al., 1996). More recently, the effectiveness of AFLP for taxonomy and genetic diversity studies has been demonstrated in a number of biological systems including bacteria (Janssen et al., 1996, 1997), fungi (Mueller et al., 1996), plants (Travis et al., 1996) and animals (Folkertsma et al., 1996). Here, the advantages of AFLP are put to use for strain differentiation and species identification in yeasts. The usefulness of the technique for studying genetic similarities of yeasts is also discussed.

\section{METHODS}

Yeast strains and media. The yeast strains used in this study are listed in Table 1. Reference strains are species type strains obtained from the Centraalbureau voor Schimmelcultures (CBS) culture collection in Delft, The Netherlands. All the yeasts in the study have been previously described (de Barros Lopes et al., 1996, 1998) except the two Saccharomyces cerevisiae laboratory yeasts, which are derived from S288C (Janssen et al., 1996). All yeasts were grown on YEPD $[1 \%(\mathrm{w} / \mathrm{v})$ yeast extract, $2 \%(\mathrm{w} / \mathrm{v})$ peptone, $2 \%$ $(\mathrm{w} / \mathrm{v})$ glucose].

Preparation of DNA template for PCR. For all species, DNA was purified using mechanical breakage with glass beads (Ausubel et al., 1994). A cell suspension from a $5 \mathrm{ml}$ culture grown in YEPD medium was resuspended in $200 \mu \mathrm{l}$ breaking buffer $[2 \%(\mathrm{v} / \mathrm{v})$ Triton $\mathrm{X}-100,1 \%$ SDS, $100 \mathrm{mM} \mathrm{NaCl}$, $10 \mathrm{mM}$ Tris (pH 8), $1 \mathrm{mM}$ EDTA (pH 8)]. The yeast cells 
were homogenized by vortexing for $3 \mathrm{~min}$ with $0 \cdot 3 \mathrm{~g}$ glass beads in the presence of $200 \mu \mathrm{l} \mathrm{phenol/chloroform/isoamyl}$ alcohol. To this, $200 \mu \mathrm{l}$ Tris $(10 \mathrm{mM}) /$ EDTA $(1 \mathrm{mM})$ buffer (pH 8) (TE) was added and, after centrifugation, the aqueous layer collected. The DNA was precipitated with ethanol and resuspended in $300 \mu \mathrm{T}$ TE buffer. RNA was digested by adding $3 \mu \mathrm{l}$ of a solution containing $10 \mathrm{mg}$ RNase $\mathrm{A} \mathrm{ml} \mathrm{m}^{-1}$ and incubated for $5 \mathrm{~min}$ at $37^{\circ} \mathrm{C}$. The DNA was extracted for a second time with $200 \mu \mathrm{l}$ phenol/ chloroform/isoamyl alcohol and ethanol-precipitated. It was resuspended in $50 \mu \mathrm{TE}$ buffer and a $10 \mu \mathrm{l}$ aliquot was used to determine the concentration by measurement of $A_{260}$.

AFLP. The AFLP reactions were performed as described by Vos et al. (1995) with some modifications. For the results shown in this study, $0.5 \mu \mathrm{g}$ yeast DNA was digested with 5 units EcoRI and 5 units $M s e I$ in RL buffer $[10 \mathrm{mM}$ Tris/acetate, $10 \mathrm{mM}$ magnesium acetate, $50 \mathrm{mM}$ potassium acetate, $5 \mathrm{mM}$ DTT (pH 7.5)] in a volume of $40 \mu \mathrm{l}$ for $3 \mathrm{~h}$ at $37^{\circ} \mathrm{C}$. MseI (50 pmol 5' GACGATGAGTCCTGAG $3^{\prime}$ and $5^{\prime}$ TACTCAGGACTCAT 3') and EcoRI (5 pmol 5' CTCGTAGACTGCGTACC $3^{\prime}$ and 5' AATTGGTACGCAGTC $\left.3^{\prime}\right)$ adaptors were ligated to the digested DNA in a total volume of $50 \mu \mathrm{l}$ using 1 unit T4 DNA ligase in RL buffer plus ATP $(1.2 \mathrm{mM})$. The reactions were incubated for another $3 \mathrm{~h}$ at $37^{\circ} \mathrm{C}$. The digested and ligated DNA was ethanolprecipitated and resuspended in $100 \mu \mathrm{l}$ Tris $(10 \mathrm{mM}) /$ EDTA $(0 \cdot 1 \mathrm{mM})$ buffer $(\mathrm{pH})\left(\mathrm{T}_{0 \cdot 1} \mathrm{E}\right)$.

The PCR reaction was performed using primers Eco RI-C ( $5^{\prime}$ AGACTGCGTACCAATTCC 3') and MseI-AC (5' GATGAGTCCTGAGTAAAC 3'). For each AFLP reaction, $10 \mathrm{ng}(2 \mu \mathrm{l})$ of the ligated DNA was amplified using $30 \mathrm{ng}$ unlabelled $M s e I-A C$ primer, $25 \mathrm{ng}$ unlabelled EcoRI-C primer and $0.5 \mu \mathrm{l}(5 \mathrm{ng}$ ) labelled EcoRI-C primer. (For 10 reactions, $50 \mathrm{ng}$ primer EcoRI-C was radioactively labelled using $10 \mu \mathrm{Ci}(370 \mathrm{kBq})\left[\gamma^{32}{ }^{32} \mathrm{P}\right] \mathrm{ATP}$ in $5 \mu \mathrm{l}$ with 1 unit T4 polynucleotide kinase. The reaction was incubated at $37^{\circ} \mathrm{C}$ for $30 \mathrm{~min}$.) Reactions were done in $20 \mu \mathrm{l} \mathrm{PCR}$ buffer containing $1.5 \mathrm{mM} \mathrm{MgCl}, 0.2 \mathrm{mM}$ dNTPs and $0 \cdot 1$ unit Taq polymerase (Gibco-BRL). A 'touchdown' cycle was used for the PCR reaction (96 well multiplate and PTC100 thermocycler; MJ Research). Denaturation was at $94{ }^{\circ} \mathrm{C}$ for $30 \mathrm{~s}$ and extension at $74{ }^{\circ} \mathrm{C}$ for $1 \mathrm{~min}$. The annealing temperature started at $64{ }^{\circ} \mathrm{C}$ and was subsequently decreased by $0.2{ }^{\circ} \mathrm{C}$ every cycle until it reached $60{ }^{\circ} \mathrm{C}$. This was followed by 10 more cycles at $60^{\circ} \mathrm{C}$ and a final 5 min extension at $74{ }^{\circ} \mathrm{C}$. The higher annealing temperature used in this study compared to other AFLP investigations was used to produce fingerprints with fewer background bands. To the completed reactions, $20 \mu \mathrm{l}$ gel loading buffer $(94 \%$ formamide, $10 \mathrm{mM}$ EDTA, $0.5 \mathrm{mg}$ xylene cyanol $\mathrm{FF} \mathrm{ml}{ }^{-1}$, $0.5 \mathrm{mg}$ bromophenol blue $\mathrm{ml}^{-1}$ ) was added. Samples were heated to $90{ }^{\circ} \mathrm{C}$ for $3 \mathrm{~min}$ and cooled on ice. Products of each amplification reaction were resolved on $6 \%$ polyacrylamide gels (Sequagel 6; National Diagnostics) at $40 \mathrm{~W}$. For the last $45 \mathrm{~min}$ of the run, the bottom buffer was $0.3 \mathrm{M}$ sodium acetate to stack the lower molecular mass bands. After drying, gels were exposed to film (Fuji-RX) at room temperature for $18-48 \mathrm{~h}$.

Other primers used in the study (results not shown) included EcoRI-A, EcoRI-AG, MseI-G and PstI-A. In all cases, one selective base was used on one primer and two selective bases on the other. It was found that using more selective bases produced less consistent results. For some combinations of primers, a pre-amplification or a lower annealing temperature was necessary to obtain acceptable results.

The presence/absence of AFLP markers was scored by eye. Analysis was performed using the NTSYS-pc software (Rohlf, 1993). Pairwise similarities were created using the Dice coefficient, which is equal to twice the number of common bands in two fingerprints over the sum of all bands. The unweighted pair group method with arithmetic averages (UPGMA) was used to cluster the results. The genetic similarities obtained were also corroborated using other clustering methods.

\section{RESULTS}

\section{Yeast strain differentiation}

Fig. 1 shows the AFLP fingerprint of a number of $S$. cerevisiae strains. These include commercial yeasts, indigenous grape juice microflora, laboratory strains and the type strain of $S$. cerevisiae. Using the single primer pair EcoRI-C and MseI-AC, many of the strains could be differentiated. Two cultures that could not be separated using this primer pair and other primers tested (results not shown), were AWRI 1017 (lane 11) and AWRI 1265 (lane 23). AWRI 1017 is a commonly used commercial wine yeast strain. Strain AWRI 1265 was isolated from equipment in a winery that uses AWRI 1017 as its inoculum strain for fermentations. These strains were also not separated using semi-specific PCR (de Barros Lopes et al., 1998). These results indicate that the strains are identical. Two other strains that could not be differentiated in this study were AWRI 729 (lane 13) and AWRI 835 (lane 16). AWRI 835 is a member of the 729 family of yeasts and is thought to be a clonal isolate of strain AWRI 729 (see de Barros Lopes et al., 1996; Henschke, 1990; Petering et al., 1988). Other 729 strains (AWRI 814, AWRI 825 and AWRI 925) that were not separated from each other by EcoRI-C/MseI-AC were differentiated using a second primer pair. The reproducibility of AFLP is seen in the fingerprints of the two opposite mating types of the laboratory strain. The two yeasts, which have identical genotypes, except at the $M A T$ locus, produced identical AFLP fingerprints (lanes 2 and 3 ).

The effectiveness of AFLP in uncovering polymorphisms is also apparent with the non-S. cerevisiae strains. All of the strains analysed in Figs 2 and 3, which include yeasts from seven genera, could be differentiated.

\section{Yeast species identification}

The results in Figs 1 and 2 demonstrate that although there are polymorphisms between strains of the same species, many of the amplified bands are shared intraspecifically. For example, for the twenty-six $S$. cerevisiae strains studied in Fig. 1, approximately $54 \%$ of the amplified fragments are monomorphic. Similarly, although the Dekkera bruxellensis yeasts appear to be more divergent, $50 \%$ of the amplified fragments 


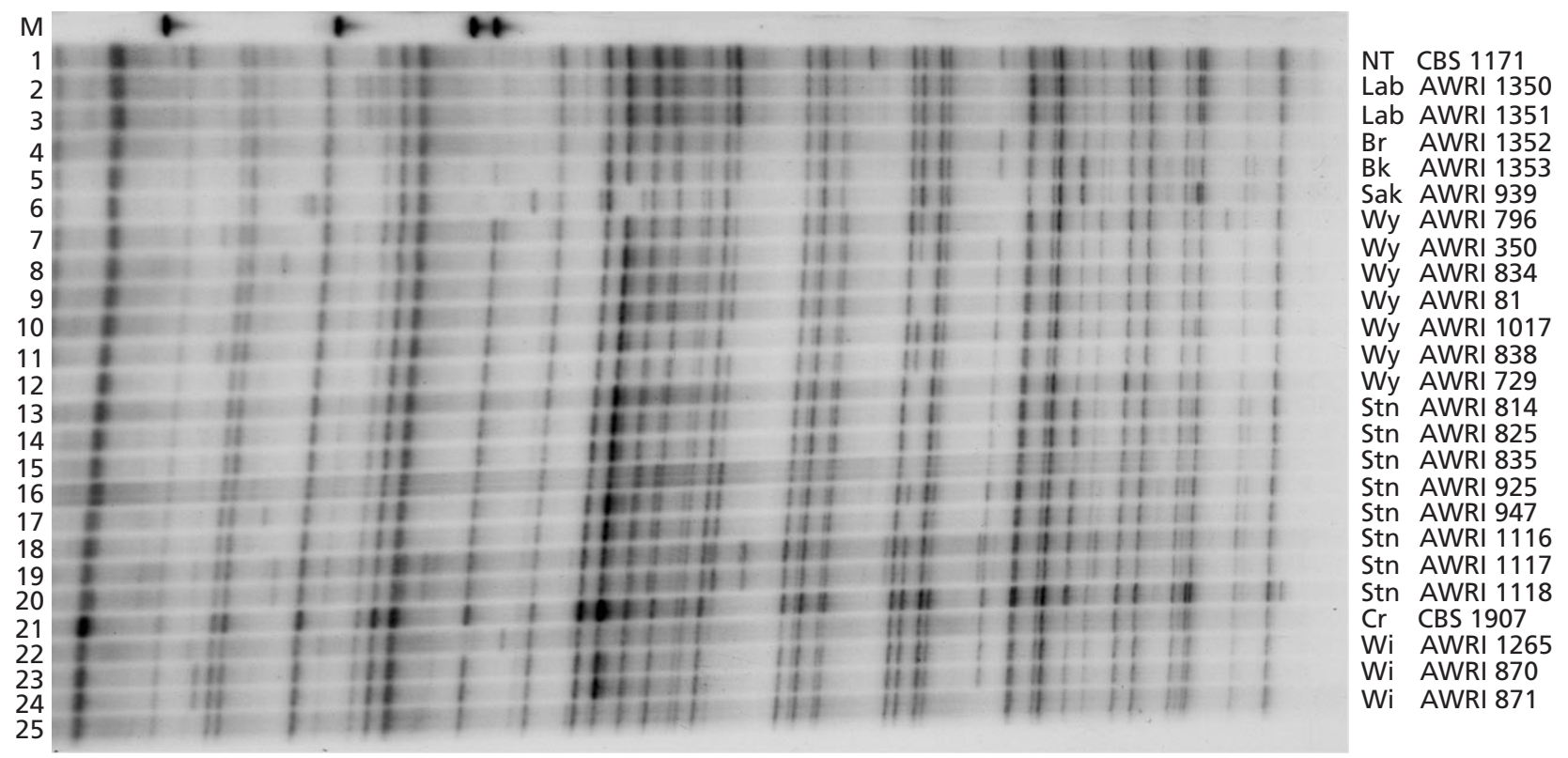

Fig. 1. AFLP fingerprints of $S$. cerevisiae strains. NT, neotype strain; Lab, laboratory strain; Br, brewers' yeast; $B k$, bakers' yeast; Sak, sake yeast; Wy, commercial wine yeast; Stn, 729 yeast; Cr, former type of C. robusta; Wi, winery isolate.

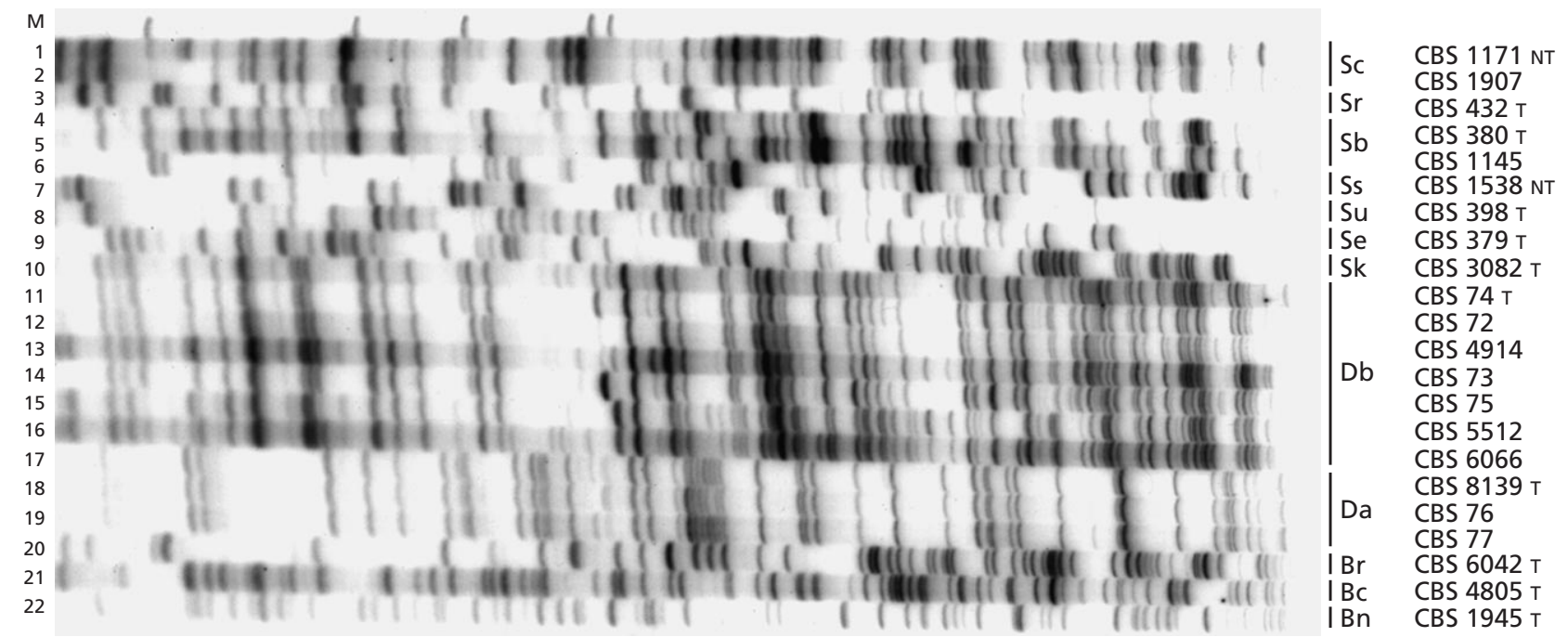

Fig. 2. AFLP fingerprints of Saccharomyces and Dekkera/Brettanomyces yeasts. Sc, S. cerevisiae; Sr, S. paradoxus; Sb, S. bayanus; Ss, S. pastorianus; Su, S. unisporus; Se, S. exiguus; Sk, S. kluyveri; Db, D. bruxellensis; Da, D. anomala; Br, B. naardenensis; $\mathrm{BC}, \mathrm{B}$. custersianus; Bn, B. nana.

are shared between all seven strains analysed (Fig. 2, lanes 10-16). The common bands amplified within a species allow identification. Further, analysis of AFLP fingerprints between related species in the same genera demonstrate that the fingerprints are unique to a particular species (Fig. 2).
The use of AFLP for identification is demonstrated in Fig. 3(a). In a previous study, a number of strains isolated from grape juice and winery equipment were identified using intron primer PCR (de Barros Lopes et al., 1998). These same strains are analysed here, and their AFLP fingerprints are compared to those gen- 
(a)

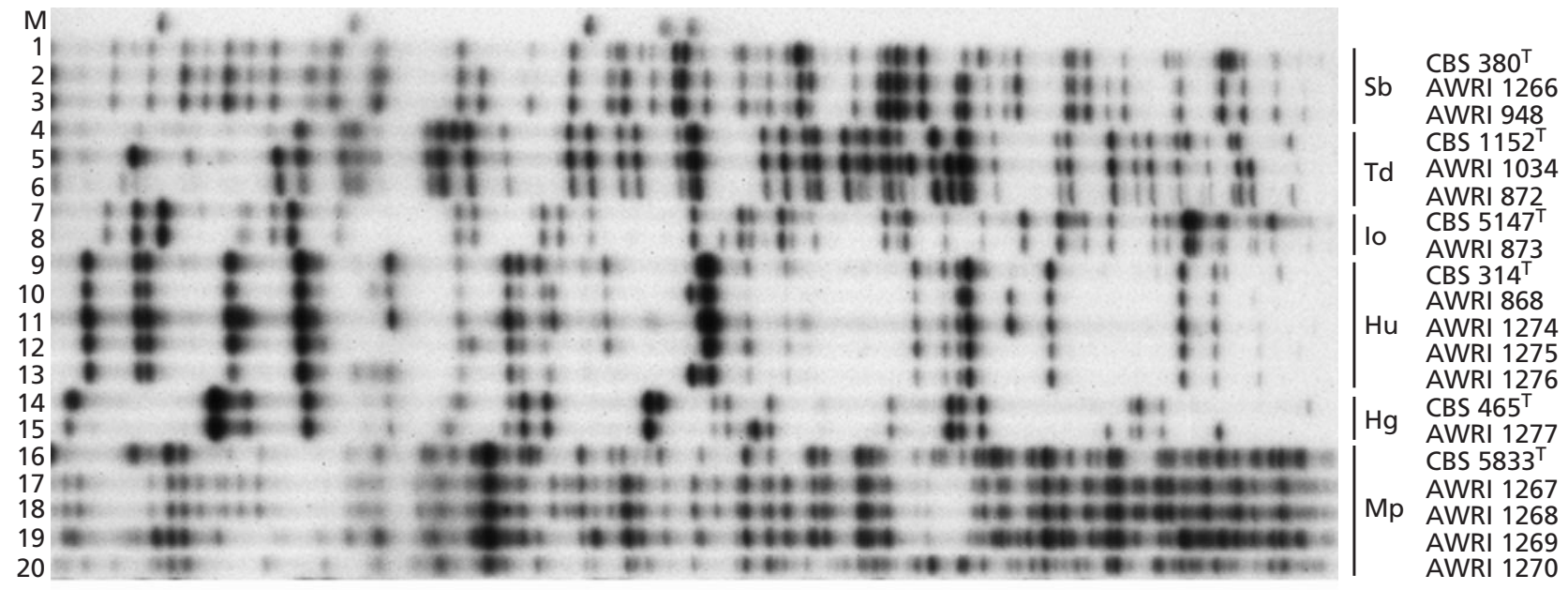

(b)

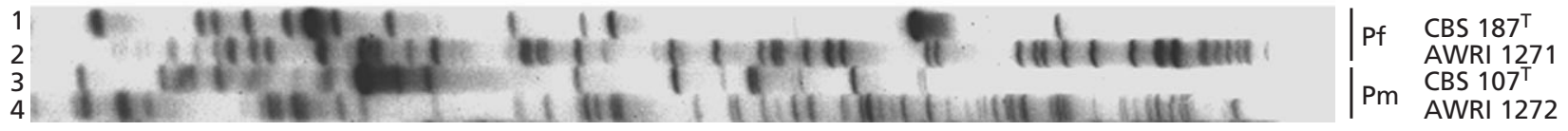

Fig. 3. Comparison of AFLP fingerprints of indigenous wine yeasts and type strains. (a) Sb, S. bayanus; Td, T. delbrueckii; Io, I. orientalis; Hu, H. uvarum; Hg, H. guilliermondii; Mp, M. pulcherrima. (b) Pf, P. fermentans; Pm, P. membranifaciens.

erated by the type strain of the same species. For all the yeasts, the similarity between the type strains and the winery isolates is clear, permitting their identity at the species level. One strain which did show notable polymorphisms when compared to its respective type strain was a Metschnikowia pulcherrima yeast, AWRI 1270 (Fig. 3a, lane 20). This increased genomic divergence was also observed with other primer pairs and with several other M. pulcherrima isolates analysed (results not shown). Based on earlier PCR results this was unexpected (de Barros Lopes et al., 1998), and indicates the increased sensitivity of AFLP. The finding supports the suggestion that heterogeneity exists within this species (Giménez-Jurado et al., 1995).

Two yeasts, AWRI 1271 and AWRI 1272, were identified using traditional physiological methods as Pichia fermentans and Pichia membranifaciens, respectively. Semi-specific PCR indicated that the genomes of these isolates were unrelated to their respective type strains, and sequence divergence of the 26S rRNA confirmed that these yeasts were not conspecific with the Pichia type strains (de Barros Lopes et al., 1998). This conclusion is also supported by the AFLP results. Fig. 3(b) shows that the AFLP fingerprints of the two wine isolates, AWRI 1271 (lane 1) and AWRI 1272 (lane 3), are unrelated to the fingerprints produced by the type strains for $P$. fermentans (lane 2) and $P$. membranifaciens (lane 4). These results confirm the heterogeneity present in some Pichia species (Noronha-da-Costa et al., 1996; Yamada et al., 1996).

\section{Genetic similarities of yeasts}

UPGMA cluster analysis was performed on several of the species in this study (Fig. 4). Analysis of the $S$. cerevisiae strains revealed that the commercial wine yeasts are more related to each other than to strains used for other purposes, with a mean similarity of $96 \cdot 6 \%$. The yeast most diverged from the commercial wine strains is the sake yeast (AWRI 939) which has a mean similarity of $83 \%$. The bakers' yeast (AWRI 1353 ) is the most related to the commercial wine yeasts with a mean similarity of $92 \cdot 3 \%$.

Cluster analysis of the D. bruxellensis yeasts also indicates the sensitivity of AFLP in determining intraspecific genetic similarities. The type strain (CBS 74) and the former type strains of Brettanomyces bruxellensis (CBS 72), Dekkera intermedia (CBS 4914) and Brettanomyces lambicus (CBS 75) are the most alike, sharing a minimum of $91.6 \%$ of the amplified fragments. The former type strains of Brettanomyces custersii (CBS 5512) and Brettanomyces abstinens (CBS 6066) (92.4\% similarity with each other) are the most diverged, with mean similarities of $79 \cdot 1 \%$ and $80 \cdot 8 \%$, respectively, when compared to the four more conserved strains. Brettanomyces intermedius (CBS 73) is intermediate in relatedness, with a mean of $85.2 \%$ similarity with the D. bruxellensis cluster and $86.2 \%$ with B. custersii/B. abstinens. Phylogenetic analysis of the same data were consistent with the UPGMA cluster analysis (results not shown) and agrees with other molecular data on these strains. A similar 
(a)

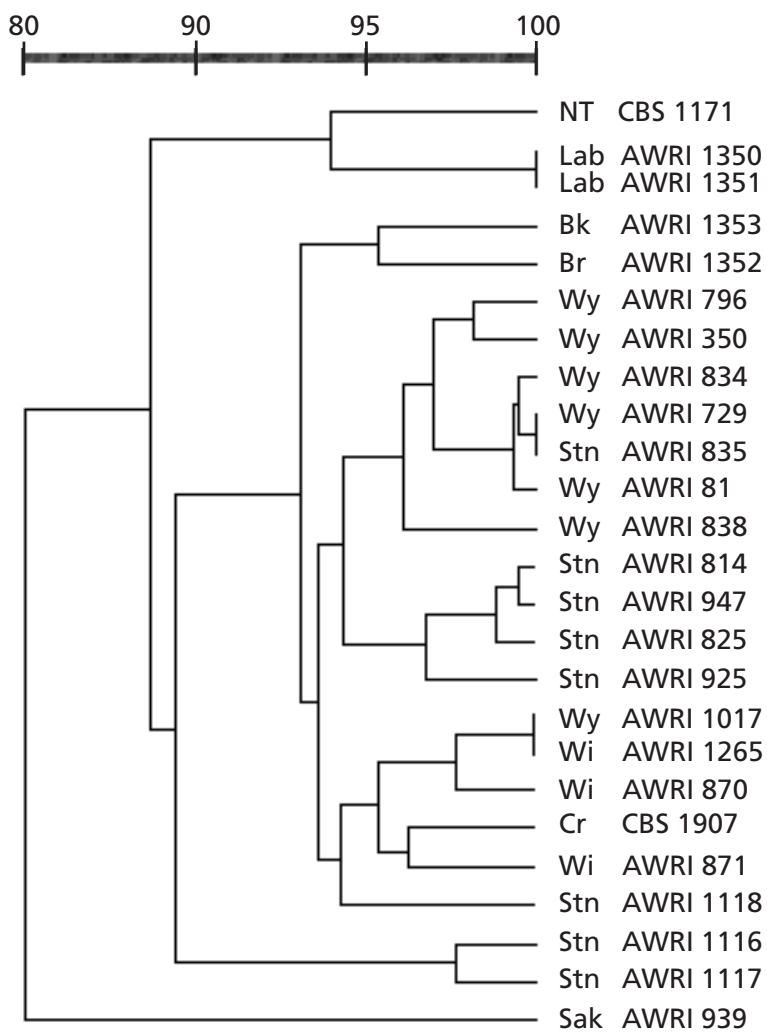

(a)

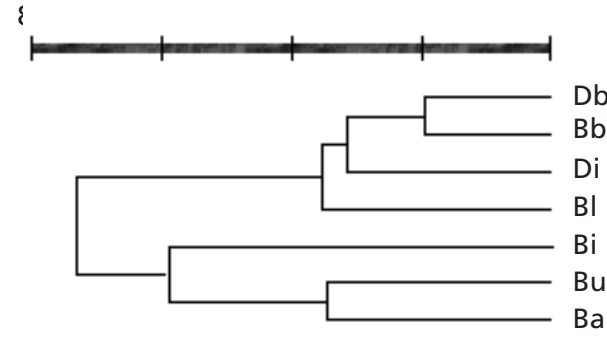

CBS $74^{\top}$

CBS 72

CBS 4914

CBS 75

CBS 73

CBS 5512

CBS 6066

Fig. 4. Cluster analysis using UPGMA. (a) S. cerevisiae strains. NT, neotype strain; Lab, laboratory strain; Bk, bakers' yeast; $\mathrm{Br}$ brewers' yeast; Wy, commercial wine yeast; Stn, 729 yeast; Wi, winery isolate; $\mathrm{Cr}$, former type of $C$. robusta; Sak, sake yeast (b) Db, D. bruxellensis; Bb, B. bruxellensis; Di, D. intermedia; $\mathrm{Bl}$, $B$. lambicus; $\mathrm{Bi}, B$. intermedius; $\mathrm{Bu}, B$. custersii; $\mathrm{Ba}, \mathrm{B}$. abstinens.

analysis was not possible on the Dekkera anomala yeasts as the variance between the three strains was minor.

The use of AFLP for analysing interspecific genetic similarities of the Saccharomyces sensu stricto yeasts was not successful. Seven primer sets were used in AFLP on the four sibling Saccharomyces sensu stricto yeasts. Analysis of AFLP fingerprints did not produce results consistent with the known genetic relatedness of these four species (data not shown).

\section{DISCUSSION}

In this research, the usefulness of AFLP in yeast strain differentiation and identification is demonstrated. With the exception of the two laboratory $S$. cerevisiae strains, all the yeasts studied have been previously analysed using semi-specific PCR (de Barros Lopes et al., 1996, 1998), and many of them have been karyotyped (Henschke, 1990; Petering et al., 1988, 1990). This allows the different methods to be compared. In addition, AFLP has been used to study intraspecific genetic similarities of strains.

The effectiveness of the method in strain discrimination is seen in the separation of the putative 729 strains. Many of these are presumed isolates of the same yeast that have been stored in different culture collections (see Table 1). Using semi-specific PCR, five of the strains were shown to be different to the commercial isolate AWRI 729 (de Barros Lopes et al., 1996). Using a single primer pair in AFLP, all the 729 strains, with the exception of AWRI 835, could be separated from AWRI 729. Several factors could account for the differences in genome structure of the 729 family. The freeze-dry method used for long-term storage of these yeasts is capable of inducing chromosome breaks. Further, mitotic chromosome rearrangements have been reported in a wild strain of $S$. cerevisiae (Longo \& Vezinhet, 1993), although the extent of this phenomenon is unresolved. For detecting chromosomal modifications of this type, chromosome karyotyping is likely to be more effective than AFLP. Interestingly, although AFLP, semi-specific PCR (de Barros Lopes et al., 1996) and initial PFGE experiments (Petering et al., 1988) were unable to discriminate between strains AWRI 729 and AWRI 835, increasing the resolution of the PFGE method uncovered a minor polymorphism in their karyotypes (Henschke, 1990). An additional mechanism of obtaining chromosome variation is genome renewal (Mortimer et al., 1994). In this process, which has been observed in several homothallic wine yeast isolates, cells are able to undergo meiosis and self-conjugation in rich media. The role of genome renewal in producing genetic diversity in the 729 family of yeasts has not been tested. Alternatively, the most likely explanation for at least the most divergent 729 strains [AWRI 1116 (Fig. 1, lane 19) and AWRI 1117 (lane 20)] is that the yeasts are not related to the commercial AWRI 729 strain.

All the non-S. cerevisiae isolates could be separated from each other. For strains of the same species, the number of polymorphisms between strains ranged from one to more than thirty from a single primer pair. Between species, few monomorphic bands were observed. Two strains that could not previously be differentiated using intron primer PCR were the Saccharomyces bayanus strains AWRI 1266 and AWRI 948 (de Barros Lopes et al., 1998). These two yeasts were isolated in different years from cold stored juice in the same winery. It was thought that they may 
be identical, but the increased sensitivity of AFLP permits their separation. The discriminatory potential of AFLP with yeasts is also highlighted by the number of polymorphisms obtained with other genera. Notably, the D. bruxellensis and $M$. pulcherrima yeasts produced similar semi-specific PCR amplification patterns (de Barros Lopes et al., 1998), but highly polymorphic AFLP fingerprints.

Since strains of the same species share many amplification fragments, AFLP is also effective for species identification. For this purpose there are no apparent advantages of using AFLP over the more rapid PCR methods (de Barros Lopes et al., 1998; Latouche et al., 1997), although the ability of AFLP to analyse a more extensive portion of the genome may uncover genetic similarities between yeasts that are not revealed using other molecular methods. For example, although Issatchenkia scutulata var. scutulata and I. scutulata var. exigua show only $24 \%$ DNA similarity as measured by reassociation experiments, the two varieties are able to mate and produce viable ascospores (Kurtzman et al., 1980). If specific regions of the genomes between these two varieties are conserved, AFLP may reveal this kinship.

AFLP has also been used to determine the genetic relatedness of yeasts (Fig. 4). UPGMA cluster analysis of the $S$. cerevisiae strains indicates that the commercial winemaking yeasts are more closely related to each other than to strains used for other purposes, including the laboratory, brewers', bakers' and sake strains. Furthermore, three indigenous isolates from Australian wineries are also related to the commercial wine strains. Apart from the sake yeast, two Epernay yeasts isolated from French wineries, AWRI 1116 and AWRI 1117, produced the most polymorphic AFLP fingerprints when compared to the commercial wine strains. It is unlikely that the reason for the variation is geographical as many of the commercial yeasts and a third Epernay yeast, AWRI 1118, were isolated from France. The importance of geographical location in predicting genetic similarity was also examined in the Hanseniaspora uvarum strains (UPGMA analysis not shown). There was no increased kinship between the two Californian isolates compared to the two Australian isolates. The absence of a correlation between geography and genome relatedness in the $S$. cerevisiae and $H$. uvarum yeasts is likely due to the influence of humans in the dispersal of wine yeasts.

Surprisingly, of the $S$. cerevisiae strains analysed, the AFLP fingerprints of the laboratory strain was most similar to the type strain, CBS 1171. The main progenitor strain of S288C, and most other laboratory strains, was stated to be a strain isolated from rotting figs in California, EM93 (Mortimer \& Johnston, 1986). It was expected that this yeast would be more closely related to the indigenous yeasts isolated from wineries, but no clear relationship between the laboratory yeasts and the winery isolates was evident. A more extensive investigation using additional primer sets and yeasts, including EM93, is currently being done to further analyse the observed similarity.

Cluster analysis of the D. bruxellensis AFLP fingerprints agrees with earlier findings on the genetic relatedness of these yeasts. Electrophoretic comparison of enzymes and DNA reassociation experiments led to the seven synonyms of $D$. bruxellensis being incorporated into a single species (Smith et al., 1990). This reclassification has since been supported by other methods including RFLP (Molina et al., 1993) and sequence analysis of mitochondrial (Hoeben et al., 1993) and ribosomal (Boekhout et al., 1994; Yamada et al., 1994) genes. However, enzyme analysis produced two separate groups amongst the strains of this species (Smith et al., 1990). The first group included the type strains of D. bruxellensis (CBS 74), B. bruxellensis (CBS 72), D. intermedia (CBS 4914) and B. lambicus (CBS 75). The second group included $B$. intermedius (CBS 73), B. abstinens (CBS 6055) and B. custersii (CBS 5512). The AFLP results are consistent with this grouping. Analysis of the mitochondrial genome structure of the Dekkera yeasts led to the seven $D$. bruxellensis synonyms being incorporated into two species, separating $B$. custersii and B. abstinens from the others (McArthur \& Clark-Walker, 1983). The differentiation of these two yeasts from the other $D$. bruxellensis strains is also supported by DNA reassociation studies (Smith et al., 1990). Furthermore, the sequence of the $B$. custersii mitochondria-encoded cytochrome oxidase subunit gene (COX2) (Hoeben et al., 1993) and 26S rDNA (Boekhout et al., 1994; Yamada et al., 1994) is different from D. bruxellensis. Again, the AFLP analysis is consistent with the increased divergence of $B$. custersii and $B$. abstinens from the other D. bruxellensis yeasts.

In this study, AFLP was also evaluated for determining the genetic similarity between closely related yeast species. Cluster analysis of the type strains of the Saccharomyces sensu stricto species was performed using the results from seven primer pairs. The AFLP fingerprints between these four species were highly polymorphic and UPGMA analysis did not produce a relationship consistent with those obtained using other methods, in particular that of DNA reassociation experiments (Vaughan Martini, 1989; Vaughan Martini \& Kurtzman, 1985). A similar difficulty in determining interspecific relatedness using AFLP has been observed with bacteria (Janssen et al., 1997).

In conclusion, AFLP is shown to be a very useful method in discriminating yeasts at both the species and subspecies level. Many of the yeasts in this study have previously been analysed using PCR (de Barros Lopes et al., 1996, 1998) and karyotyping (Henschke, 1990; Petering et al., 1988, 1990). Although karyotyping has been shown to be a useful method for differentiating commercial strains of $S$. cerevisiae, it is of limited use for discriminating species with fewer chromosomes. The advantages of AFLP over other methods are also 
its reproducibility (Janssen et al., 1996; Jones et al., 1997) and its widespread application across all phyla (Janssen et al., 1996, 1997; Folkertsma et al., 1996; Mueller et al., 1996; Otsen et al., 1996; Travis et al., 1996). Results described here indicate the value of AFLP in studying the intraspecific genetic relatedness of yeasts. Although initially more labour-intensive than other PCR techniques, the amount of information that can be obtained by using multiple sets of primers from a single restriction digestion/ligation is extensive. The main limitation of AFLP in yeast systematics may be its inability to establish genetic similarities between species. For this, gene sequence analysis remains the method of choice (Hoeben et al., 1993; Kurtzman, 1992; Palumbi \& Baker, 1994). However, sequence analysis of a single genetic locus can lead to erroneous conclusions on the relatedness of species (Palumbi \& Baker, 1994) and this is especially relevant with hybrid yeast species (Peterson \& Kurtzman, 1991). Sequencing of both monomorphic and polymorphic fragments obtained by AFLP should lead to a better understanding of the AFLP results in terms of interspecific relationships, providing an alternative to single sequence comparisons. In turn, the method may lend itself to obtaining an improved understanding of the relationship between the biological and phylogenetic species concepts.

\section{ACKNOWLEDGEMENTS}

We thank Anne Morgan, Angelo Karakousis and Philip Ganter for assistance with clustering analysis, and Sonia Dayan, Jodie Kretschmer and Garry Parker for helpful discussions.

\section{REFERENCES}

Ausubel, F. M., Brent, R., Kingston, R. E., Moore, D. D., Seidman, J. G., Smith, J. A. \& Struhl, K. (1994). Current Protocols in Molecular Biology, vol. 2. New York: Wiley.

Barnett, J. A., Payne, R. W. \& Yarrow, D. (1990). Yeasts: Characteristics and Identification, 2nd edn. Cambridge: Cambridge University Press.

de Barros Lopes, M. A., Soden, A., Henschke, P. A. \& Langridge, P. (1996). PCR differentiation of commercial yeast strains using intron splice site primers. Appl Environ Microbiol 62, 4514-4520.

de Barros Lopes, M., Soden, A., Martens, A. L., Henschke, P. A. \& Langridge, P. (1998). Differentiation and species identification of yeasts using PCR. Int J Syst Bacteriol 48, 279-286.

Boekhout, T., Kurtzman, C. P., O’Donnell, K. \& Smith, M. T. (1994). Phylogeny of the yeast genera Hanseniaspora (anamorph Kloeckera), Dekkera (anamorph Brettanomyces), and Eeniella as inferred from partial $26 \mathrm{~S}$ ribosomal DNA nucleotide sequences. Int $J$ Syst Bacteriol 44, 781-786.

Folkertsma, R. T., Rouppe van der Voort, J. N. A. M., de Groot, K. E., van Zandvoort, P. M., Schots, A., Gommers, F. J., Helder, J. \& Bakker, J. (1996). Gene pool similarities of potato cyst nematode populations assessed by AFLP analysis. Mol PlantMicrobe Interact 9, 47-54.
Ganter, P. F. \& Quarles, B. (1997). Analysis of population structure of cactophilic yeast from the genus Pichia: $P$. cactophila and P. norvegensis. Can J Microbiol 43, 35-44.

Giménez-Jurado, G., Valderrama, M. J., Sá-Nogueira, I. \& SpencerMartins, I. (1995). Asssessment of phenotypic and genetic diversity of the yeast genus Metschnikowia. Antonie Leeuwenhoek 68, 101-110.

Henschke, P. (1990). Evaluating wine yeasts for improved wine quality. In Proceedings of the Seventh Australian Wine Industry Technical Conference, pp. 157-165. Edited by P. Williams, D. Davidson \& T. Lee. Adelaide: Australian Industrial Publishers.

Hoeben, P., Weiller, G. \& Clark-Walker, G. D. (1993). Larger rearranged mitochondrial genomes in Dekkera/Brettanomyces yeasts are more closely related than smaller genomes with a conserved gene order. J Mol Evol 36, 263-269.

Janssen, P., Coopman, R., Huys, G., Swings, J., Bleeker, M., Vos, P., Zabeau, M. \& Kersters, K. (1996). Evaluation of the DNA fingerprinting method AFLP as a new tool in bacterial taxonomy. Microbiology 142, 1881-1893.

Janssen, P., Maquelin, K., Coopman, R., Tjernberg, I., Bouvet, P., Kersters, K. \& Dijkshoorn, L. (1997). Discrimination of Acinetobacter genomic species by AFLP fingerprinting. Int $J$ Syst Bacteriol 47, 1179-1187.

Johnston, J. R. \& Mortimer, R. K. (1986). Electrophoretic karyotyping of laboratory and commercial strains of Saccharomyces and other yeasts. Int J Syst Bacteriol 36, 569-572.

Jones, C. J., Edwards, K. J., Castaglione, S. \& 19 other authors (1997). Reproducibility testing of RAPD, AFLP and SSR markers in plants by a network of European laboratories. $\mathrm{Mol}$ Breed 3, 381-390.

Kurtzman, C. P. (1992). rRNA sequence comparisons for assessing phylogenetic relationships among yeasts. Int J Syst Bacteriol 42, 1-6.

Kurtzman, C. P. \& Phaff, H. J. (1987). Molecular taxonomy. In Biology of Yeasts, pp. 63-94. Edited by A. H. Rose \& J. S. Harrison. London: Academic Press.

Kurtzman, C. P., Smiley, M. J. \& Johnson, C. J. (1980). Emendation of the genus Issatchenkia Kudriavzev and comparison of species by deoxyribonucleic acid reassociation, mating reaction, and ascospore ultrastructure. Int J Syst Bacteriol 30, 503-513.

Latouche, G. N., Daniel, H. M., Lee, C. C., Mitchell, T. G., Sorrell, T. C. \& Meyer, W. (1997). Comparison of the use of phenotypic and genotypic characteristics for identification of species of the anamorph genus Candida and related teleomorph yeast species. J Clin Microbiol 35, 3171-3180.

Lavallée, F., Salvas, Y., Lamy, S., Thomas, D. Y., Degré, R. \& Dulau, L. (1994). PCR and DNA fingerprinting used as quality control in the production of wine yeast strains. Am J Enol Vitic 45, 86-91.

Longo, E. \& Vezinhet, F. (1993). Chromosomal rearrangements during vegetative growth of a wild strain of Saccharomyces cerevisiae. Appl Environ Microbiol 59, 322-326.

McArthur, C. R. \& Clark-Walker, G. D. (1983). Mitochondrial DNA size diversity in the Dekkera/Brettanomyces yeasts. Curr Genet 7, 29-35.

Molina, F. I., Shen, P. \& Jong, S.-C. (1993). Validation of the species concept in the genus Dekkera by restriction analysis of genes coding for rRNA. Int $J$ Syst Bacteriol 43, 32-35.

Mortimer, R. K. \& Johnston, J. R. (1986). Genealogy of principal strains of the yeast genetic stock center. Genetics 113, 35-43.

Mortimer, R. K., Romano, P., Suzzi, G. \& Polsinelli, M. (1994). Genome renewal: a new phenomenon revealed from a genetic 
study of 43 strains of Saccharomyces cerevisiae derived from natural fermentation of grape musts. Yeast 10, 1543-1552.

Mueller, U. G., Lipari, S. E. \& Milgroom, M. G. (1996). Amplified fragment length polymorphism (AFLP) fingerprinting of symbiotic fungi cultured by the fungus-growing ant Cyphomyrmex minutus. Mol Ecol 5, 119-122.

Noronha-da-Costa, P., Rodrigues, C., Spencer-Martins, I. \& Loureiro, V. (1996). Fatty acid patterns of film-forming yeasts and new evidence for the heterogeneity of Pichia membranaefaciens. Lett Appl Microbiol 23, 79-84.

Otsen, M., den Bieman, M., Kuiper, M. T. R., Pravenec, M., Kren, V., Kurtz, T. W., Jacob, H. J., Lankhorst, AE. \& van Zutphen, B. F. M. (1996). Use of AFLP markers for gene mapping and QTL detection in the rat. Genomics 37, 289-294.

Palumbi, S. R. \& Baker, C. S. (1994). Contrasting population structure from nuclear intron sequences and mtDNA of humpback whales. Mol Biol Evol 11, 426-435.

Petering, J., Langridge, P. \& Henschke, P. (1988). Fingerprinting wine yeasts: the application of chromosome electrophoresis. Aust NZ Wine Ind J 3, 48-52.

Petering, J., Langridge, P. \& Henschke, P. (1990). Identification of yeast strains by molecular biology techniques. In Ninth International Oenological Symposium, Cascais, Portugal, pp. 178-199. Breisach, Germany: International Association for Modern Winery Technology and Management.

Peterson, S. W. \& Kurtzman, C. P. (1991). Ribosomal RNA sequence divergence among sibling species of yeasts. Syst Appl Microbiol 14, 124-129.

Price, C. W., Fuson, G. B. \& Phaff, H. J. (1978). Genome comparison in yeast systematics: delimitation of species within the genera Scwanniomyces, Saccharomyces, Debaryomyces, and Pichia. Microbiol Rev 42, 161-193.
Rohlf, F. J. (1993). NTSYS-pc. Numerical taxonomy and multivariate analysis system. New York: Exeter Software.

Smith, M. T., Yamazaki, M. \& Poot, G. A. (1990). Dekkera, Brettanomyces and Eeniella: electrophoretic comparison of enzymes and DNA-DNA homology. Yeast 6, 299-310.

Thomas, C. M., Vos, P., Zabeau, M., Jones, D. A., Norcott, K. A., Chadwick, B. P. \& Jones, J. D. (1995). Identification of amplified restriction fragment length polymorphism (AFLP) markers tightly linked to the tomato Cf-9 gene for resistance to Cladosporium fulvum. Plant J 8, 785-794.

Travis, S. E., Maschinski, J. \& Keim, P. (1996). An analysis of genetic variation in Astragalus cremnophylax var. cremnophylax, a critically endangered plant, using AFLP markers. Mol Ecol 5, 735-745.

Vaughan Martini, A. (1989). Saccharomyces paradoxus comb. nov., a newly separated species of the Saccharomyces sensu stricto complex based upon nDNA/nDNA homologies. Syst Appl Microbiol 12, 179-182.

Vaughan Martini, A. \& Kurtzman, C. P. (1985). Deoxyribonucleic acid relatedness among species of the genus Saccharomyces sensu stricto. Int J Syst Bacteriol 35, 508-511.

Vos, P., Hogers, R., Bleeker, M. \& 8 other authors (1995). AFLP: a new technique for DNA fingerprinting. Nucleic Acids Res 23, 4407-4414.

Yamada, Y., Matsuda, M., Maeda, K. \& Mikata, K. (1994). The phylogenetic relationships of species of the genus Dekkera van der Walt based on the partial sequences of $18 \mathrm{~S}$ and $26 \mathrm{~S}$ ribosomal RNAs (Saccharomycetaceae). Biosci Biotechnol Biochem 58, 1803-1808.

Yamada, Y., Higashi, T. \& Mikata, K. (1996). Should Petasospora Boidin et Abadie (Saccharomycetaceae) be retained? - the phylogeny based on the partial sequences of $18 \mathrm{~S}$ and $26 \mathrm{~S}$ ribosomal RNAs. Biosci Biotechnol Biochem 60, 818-822. 